\title{
Defect of memorizing of hippocampal-mammillary origin: a review
}

\author{
JACQUES BARBIZET
}

Paris

The history of 'amnésie de mémoration' has evolved through three stages. The first, a clinical one, started in 1887 with Korsakoff's description of a morbid association characterized by two basic criteria. These were, first, a psychological disorder associated with degenerative polyneuritis, and secondly a mental syndrome which included a special form of amnesia. This syndrome captured the attention of psychiatrists like Seglas (1895), Régis (1923), and Dupré (1903) who looked on the memory disorder as a mental aberration and stressed the interest of the psycho-polyneuritis syndrome, the clinical actuality of which had been fully accepted. However, the semeiotic significance of the amnesic syndrome described by Korsakoff was not overlooked by authors like Bonhoeffer (1904) in Germany and Chaslin $(1895 ; 1912)$ in France. As pointed out by Angelergues (1958), Chaslin must be praised for emphasizing the importance of Korsakoff's mental syndrome which he was to define as a symptomatic triad of amnesia, fabrication, and disorientation.

Jean Delay, in his book on disorders of memory (1942), directed interest to the type of amnesia, and his thorough analysis led him to discard the conventional expression of 'fixation amnesia' and to adopt that of 'amnésie de mémoration' (defect of memorizing). A further stage in the elucidation of this type of amnesia had been started a few years earlier with the work of Gamper (1928), who insisted on the role of the mammillary bodies, and this has developed further through the more recent works of Scoville and Milner (1957) and of Penfield and Milner (1958) on the role of the gyri hippocampi. These studies now lead to the third stage (also made possible by the present development of cybernetic machines with memory capabilities), the study of remembering in normal man.

We know that remembering involves memorizing, retention, and recalling, and by casting a new light on the first of these three, a study of pathological conditions may enable us to analyse better the processes which go to constitute the complex mental activity referred to as memory.

\section{CLINICAL FEATURES}

Amnésie de mémoration is characterized by the inability to build new memories as opposed to the preservation of those previously fixed, and this type of amnesia is often associated with fabrication, including misrecognition and some disorientation. It has clearly defined features. The patient faces a situation, perceives and construes it, and reacts normally, but he is unable to effect the neuronal changes required to memorize, so that after a few seconds he will not remember what he has just experienced. Examples of such 'gradual forgetfulness' are countless: the patient has forgotten the meal he has just eaten, the visit he has just been paid, the question he has just been asked, the page he has just read, the hiding place where an object has been concealed a few minutes earlier, the object he has been shown and asked to remember, and so on. One patient will not remember an application of faradization, although painful, and another will have no recollection of yesterday's air encephalography.

Memory tests clearly demonstrate this dissociation: the patient is able to reproduce on a draught-board the distribution of men he sees on another board if ceaselessly referring to the model and if proceeding one move at a time, but three minutes later he is unable to reproduce by memory the location of three or even two men. It is of interest to note that the "capability of immediate memory' as assessed from the number of figures or of syllables reproduced immediately on hearing them remains quite good, viz., about six digits for patients in their fifties. Therefore, in such patients the condition does not affect immediate repetition but a more delayed type of memory, such as is required for an active memorizing process. Hence the term 'amnésie de mémoration' proposed by Delay (1942), which is preferred to the term 'fixation amnesia'.

Owing to this failure to memorize, the patient gathers no new acquisitions after the illness develops so that the period of retrograde amnesia widens from day to day. To a certain extent therefore the duration 
of amnesia determines the date of onset of the causative condition, and this will coincide accurately with the appearance of the responsible brain lesions. Thus, Maurice remembers the past 10 years of his life accurately enough except that he has retained no memory of the past year. When reminded of the refrigerator he bought eight months ago, or of a trip driving his relatives' car five months ago, he has retained no recollection of these events. His memory gap coincided with the appearance of pyloric stenosis with acute malnutrition, superimposed on a background of chronic alcoholism. Polyneuritis developed a few months later.

The amnesic gap is not due to the fact that the patient has forgotten but that he has not memorized. So much is this the case that no information can be obtained from him either about the history of his illness or of his various periods in hospital. This disorder involves also a spatial disorientation which makes the patient unable to locate his bed or his room. There is also a disorientation in time, so that a Korsakovian is liable to reduce a period actually covering several months to a few days.

Though the lack of fixation is quite often a total one, it can also be partial. This remaining capacity for possible memorizing varies greatly with different patients. It can be a mere vague or unexpressed recollection, as in one Korsakoff patient who disliked electrical treatment and would be upset and angry as soon as he saw the equipment, although he then maintained that this was the first time he had seen it. Other patients will be able, but after many repetitions, to remember such simple information as the name of the hospital or the doctor, but these few and fragmentary acquirements will not enable them to maintain an outline of daily events, most of which will not be remembered at all.

With no capacity to fix new elements, such patients live from the items memorized and fixed before their disability developed.

It should be noted and emphasized that this stock of old memories remains relatively intact. The patient keeps at his disposal his native language and those others he may have learnt in his youth; he identifies and can quote by memory poems he used to know. This holds true also for songs. He retains his own aptitudes and physical abilities, and such patients will still be able to knit or to play chess, though they are respectively unable to learn a new pattern or a new game, even though of a much simpler type. Korsakoff reported the case of an author who could describe perfectly the literary works completed before his illness, but who, when it came to a short story started just before the disease set in, could only remember the beginning: he had no idea of the way it was supposed to develop or to end.
Such patients therefore who no longer fix the present live constantly in a past which preceded the onset of their illness. Their disengagement from the present is, however, far from complete. Some are conscious of the disorder of memory, like Emilienne, who said: 'When I watch closely I know, but I soon forget. My brain feels like a sieve, I forget everything. Even in my tiny room, I keep losing things. It all fades away'. Questioned on some events of the previous day, most often she will merely say: 'I don't remember'. However, if one insists and gives her some details of these events, this stirs up some old memories which, mixed with the information just received, lead to an erroneous answer, sometimes of $\overline{\bar{n}}$ simple paramnesia, and sometimes a more elaborate and fabricated story; she remains hesitant, however, and unsure of her answer. Confronted with a doctor she saw the day before, she says she does not recognize him, but when pushed she answers: 'I must have seen him last summer in Brehat'. When asked whether she is sure of this the answer is No. Thus, amnésie de mémoration may be accompanied by some awareness of memory difficulty. The param- iv nesia, misrecognition, and fabrication observed in such cases are often suggested to a patient who has little confidence in his own answers.

In other instances, the patient is not aware of his own inability to fix new facts, and consequently does not criticize his answers when these are drawn from past memories and are used to clothe today's epo vironment and acquaintances. Thus, Germaine mis. $\vec{\theta}$ takes the head nurse for her relative and the medic student for her daughter. To Maurice, all doctors are citizens from Murat, a town in his native Cantal. Both patients are unable to memorize the present but can tell without mistakes the events of their childhood, and it seems that fabrication is with them an attempt to meet present situations using old memories in the absence of new ones, the acquirement of which has become impossible. These various types of reaction will make it easier to understand the way in which confusion may conceal memory difficulties.

Pierre, a salesman in alcoholic beverages, abruptly fell into a coma for several hours and experienced $\dot{0}$ severe mental confusion on waking up. A fortnight later, in addition to Parinaud's ophthalmoplegia, $\delta$ there remained a condition of agitation with $₹$ delirium. Pierre, visibly euphoric, pretends he $\mathrm{O}$ knows doctors and medical students; he does not want to stay in bed and addresses the medical o student as if he were a doctor himself and must attend to other patients. Later on, he talks to his or room-mates as though he were their commanding $N$ officer, relieves men, gives orders, is mindful of their $\mathrm{N}$ future, and thinks he is in the Sahara or Morocco. 
He is completely disorientated in time and space; but he still knows his wife who comes to see him. Ten minutes later, however, he will not remember her visit. After a few days he is quieter but the interpretative delirium and fabrications continue: he is a commanding officer in the air force; he controls 100 planes and has fought the Japanese. He is still disorientated in time and space and his old memories are few in number, inaccurate, and inconsistent. He has no ability to acquire new knowledge and if he correctly repeats the description and details given to him about a watch he is shown three minutes later he can no longer remember them and seizes the watch, claiming it belongs to him. However, he can immediately repeat six digits correctly.

It is interesting to note that this severe confabulatory delirium subsided in a few weeks to leave only a few misrecognitions and compensatory fabrications like those of the other patients described. These will in turn disappear, and memory tests will show a gradual return of limited memory capabilities. The patient retains a total amnesia for the first six weeks of his illness.

Apart from this basic disorder of amnésie de mémoration, it is usual in Korsakoff's syndrome to find disorders of temper or mood. According to Angelergues (1958), these are controlled by two factors: the patient's previous personality and the nature of the aetiological factor. Alcohol addicts may show either euphoric elation, or irritability to the point of explosive fits of anger. In other patients there may be a prevailing anxiety with depression and a desultory type of confabulation. Another group, mostly that of presbyophrenics, shows apathetic indifference.

Although the occurrence of this defect of memorizing is a well-established clinical fact, and although the associated disorders also occur so constantly that no one would today deny the existence of Korsakoff's syndrome, it still seems necessary to define its limitations and its associations.

The coexistence of confusion with Korsakoff's syndrome is frequent but this should not be considered a constant feature and it has to be evaluated separately. Moreover, as has been shown in the case of Pierre, it is not infrequent to see an initial confusion subside to give way to the amnesia syndrome, the analysis of which was impossible during the stage of confusion. Further, as has already been pointed out, the failure of memorizing may be one of the factors which lead to mental confusion.

The same comments may be made regarding the varying degrees of dementia which may be found in association with Korsakoff's syndrome. The same retrograde amnesia is found, but in addition there is a degradation of memories and of reactions acquired before the lesions responsible for the syndrome. In such dementia there is impoverishment of the total store of memories, and also selective deterioration in the functions of language and activity which lead to various stages and types of aphasia, agnosia, or apraxia.

Thus, when memory disorders are but one of the constituent factors of confusion or of insanity, the clinical picture has extended far beyond the scope of Korsakoff's syndrome. At times it may be dimmed by associated lesions, but the basic characteristic of Korsakoff's syndrome remains the inability to memorize. This condition develops under the influence of various lesions.

\section{AETIOLOGY}

Although initially described by Korsakoff as a complication of chronic alcoholism, the mental syndrome discussed above also appears in other circumstances, and Henri Ey's (1954) view is that it should no longer be defined as a mere alcoholic psychosis. However, chronic alcoholism is still the largest purveyor of Korsakoff's syndrome and we now know that it acts by way of related deficiencies in which the want of thiamine plays a significant but not exclusive part. Korsakoff's syndrome occurs in various ways. It may appear as one element in Gayet-Wernicke's deficiency encephalopathy where the amnesia is associated with mental confusion, tonic motor disorders, and ocular palsies. On the other hand it may present as the after-effect of an encephalopathy which reacted favourably to thiamine, or as a confabulatory amnesia which is but a chronic mental effect of Gayet-Wernicke's disease. In other cases, Korsakoff's mental syndrome becomes the major element in a psychic disorder which developed insidiously during an episode of polyneuritis; or in relation to cirrhosis of the liver; or abruptly after an attack of delirium tremens.

Closely related to this relatively homogeneous group of deficiency encephalopathies may be mentioned the confabulatory amnesic state which may occur in confusional conditions of toxic (e.g., $\mathrm{CO})$ or infectious origin.

A second aetiological group is concerned with the dementias. Thus, Wernicke's presbyophrenia is characterized by a variable background of psychosis (usually moderate in degree), with a typical picture of fabricational amnesia and the loss of all ability to memorize current events. Such psychotic syndromes are of frequent occurrence in old people, and the deficiency of memorizing may prevail to such an extent that it becomes difficult to distinguish the condition from Korsakoff's syndrome. This difficulty 
has induced Bessières (1948) to suggest the name of 'Wernicke-Korsakoff's syndrome' for such forms.

Head injuries present a third group of patients with a defect in memorizing. Countless studies have been devoted to this subject since Kalberlah (1904) first observed Korsakoff's syndrome after trauma to the skull. Roussy and Lhermitte (1916) and Bouttier (1918) reported interesting case histories in this field; Flament (1957), in a recent paper, presented a thorough study of fabrication in cases of traumatic Korsakoff syndromes, with special emphasis on the frequency of fantasies about the circumstances of the accident. Ritchie Russell (1959) recently published an important monograph on the same subject.

In one of our cases, the patient, Emmanuel, a man aged 31 fell from his bicycle and was comatose for 48 hours. One and a half months after his accident he remembered nothing of the period since the injury. Memory tests showed good immediate perception and memory, but a poor score in tests of retention for longer periods. Thus, if he managed to memorize five items after 60 seconds, 15 minutes later his score showed a $50 \%$ loss. This loss would be complete the next day when he would have forgotten the test as well as a visit from his sister and son. Six months later everything was back to normal and memory tests were performed properly, and the preservation of new memories was normal. Emmanuel also suffered from retrograde amnesia, a phenomenon often observed in post-traumatic amnesia.

The fourth group of cases is those with brain tumours. Angelergues (1958) mentions some characteristics of the Korsakoff syndrome due to cerebral tumour. Thus, clouding of consciousness is often evident, and there is greater variation in the syndrome and a tendency to transient abnormalities, with later progression to a confused stuporous or comatose condition. The interest of Korsakoff's syndrome developing with intracranial tumours rests on the anatomical findings.

Finally, a last group is that of amnésie de mémoration seen after bilateral ablation of the hippocampus and of the gyrus hippocampi by surgery in which the amnesia may be compared with that during certain temporal lobe epileptic fits in which events have been experienced but not memorized (automatic behaviour), and may be interpreted as a temporary failure of the normal functions of the temporal lobes and perhaps more especially of the gyri hippocampi.

This review demonstrated that disorders which selectively affect memorizing will occur under the influence of different pathogenic factors. Whatever the cause, however, these disorders lead to a failure to recall information received or events experienced a few minutes or a few hours earlier and, sub- sequently, a permanent retrograde amnesic gap for the period during which the disorder remains. This impossibility of acquiring new knowledge contrasts with the preservation of normal perception and the capabilities of immediate memory as well as with the preservation of items memorized before the $D$ lesions appeared. All case histories are not identical but they all have this common pattern of amnesie de mémoration which can be supplemented by a variable amount of fabrication, retrograde amnesia, $\stackrel{-}{\Rightarrow}$ and even disorders of the aphaso-apraxo-agnosia $\stackrel{\vec{s}}{\rightarrow}$ type. In spite of these varied causes, the constancy of the defect in memorizing is probably due to the fact that this syndrome is not controlled by the cause but by the localization of lesions which impair or $\mathbb{D}$ destroy structures which are essential to certain aspects of remembering.

\section{PATHOLOGICAL ANATOMY}

Two anatomical structures at the base of the brain seem to play a significant part in this defect of memorizing - the mammillary body and the hippo- of campus - and the clinical connexion is a relativel $i v$ recent discovery. Korsakoff suggested that the $\vec{N}$ psychic disorders he described were due to degenerof tion of the subcortical association tracts, but the only case he studied with Serbsky (Korsakoff and Serbsky, 1892) revealed only neuritic lesions, and 8 음 proliferation of connective tissue at spinal cord leve No lesions of the brain were seen. After him, authote. $\vec{\varphi}$ who studied the pathological anatomy of this syndrome adhered to the description of cortical lesions. Although atrophy of the mammillary bodies was described by Gudden in 1896, it was not until the year 1928 that their role was referred to by Gamper in relation to the amnesia of Korsakoff's syndrome. In an anatomical study involving 16 cases, Gamper showed that the injury of the mammillary bodies contrasted with the integrity of the brain cortex.

The responsibility of the hippocampus in fixation amnesia was assessed at a still later date. Primarily suggested by anatomical and clinical observations on bilateral destruction of the gyri hippocampi (Campbell and Biggart, 1939; Grünthal, 1923; Conrad and Ule, 1951; Glees and Griffith, 1952), it has been confirmed by Scoville at operation. Scoville and Milner (1957) reported disorders of memorizing after therapeutic bilateral resection of $D$ the hippocampal area in mental patients. Terzian and Dalle Ore (1955), Walker (1957), and finally Penfield N and Milner (1958) were to confirm these findings.

LESIONS OF THE MAMMILLARY BODIES The connexion $\mathrm{N}$ of cases of amnésie de mémoration with injuries of the 
mammillary body have been most clearly demonstrated in relation to alcoholic encephalopathies and in tumours of the base of the brain. In a remarkably documented paper published in 1958 all the arguments supporting Gamper's mammillary theory were confirmed by Delay, Brion, and Elissalde (1958a) in connexion with an anatomical and clinical survey of eight cases of Korsakoff's syndrome of alcoholic origin with lesions of the mammillary bodies but without significant injury to the brain cortex.

1 Lesions shown in Korsakoff's syndrome are constantly and selectively located in the mammillary tubercles. They are mostly glio-vascular and occasionally neuronal lesions. There may be associated lesions of the subependymal substantia grisea of the hypothalamus and brain-stem from the anterior commissure to the pons.

2 There are no more cortical lesions in their cases than in those described by Gamper (1928) or in two-thirds of the cases described by Malamud and Skillicorn (1956). An association with neuronal or cortical lesions does at times occur, but this merely reflects an associated intellectual degradation which also appears frequently in Korsakovians.

3 The anatomical process seen in Korsakoff's disease, histologically as well as topographically, is very close to that of Wernicke's encephalopathy. The difference is a matter of degree; it is less acute and the lesions are much less haemorrhagic, with less diffusion to the diencephalon and brain-stem. As regards lesions, mammillary injuries are the true common denominator of both conditions.

Tumours of the base may also give rise to the most genuine of Korsakoff's syndromes. Since the two cases reported by Baruk in 1926, a great many others have been reported and reviewed by Angelergues (1958): glioblastoma, craniopharyngioma and metastases, which, when involving the floor of the third ventricle, may destroy the mammillary bodies and their connexions. In this respect, the survey of Williams and Pennybacker (1954) of 180 cases of brain tumour in various sites is very interesting, as the authors reported 26 observations on cases with prominent memory disorders: 15 of these were of craniopharyngioma which developed in the third ventricle and the patients showed memory disorders of the Korsakoff type, and in some a genuine Korsakoff's syndrome, while personality and intelligence were preserved.

Amnesic conditions observed in connexion with lesions of other parts of the brain are certainly of a different type and are related either to frontal inattention, to a general deterioration, or to language degradation. The type of injury varies in every case. Mammillary bodies can be invaded and destroyed or simply compressed by the tumour. Adjacent structures are often invaded, but nevertheless all these observations of basal tumours significantly implement the theory of a diencephalic origin of memorizing disorders with retrograde amnesia.

The existence of Korsakoff's syndrome has also been reported following wounds of the hypothalamus. Kleist (1934) reported several such cases with anatomical confirmation. Bender, Curran, and Schilder (1938) and Bender, Furlow, and Teuber (1949) described a case in which a shell splinter penetrated the third ventricle, and von Czechmanec (1954) a similar case in which a grenade splinter had lodged in the hypothalamic-hypophyseal area.

This aetiological survey of the mammillary theory can be continued with the report of psychic syndromes identical in every respect to Korsakoff's description but following mammillary lesions of encephalitic, vascular, traumatic, or senile origin. It should be noted, however, that in such cases the diffusion of lesions often interferes with the study of the anatomical correlations.

LESIONS OF THE GYRI HIPPOCAMPI Grünthal (1947) reported a case of rapidly developing psychosis in which the necropsy revealed bilateral softening of Ammon's horns. This fact was confirmed in a similar case of senile insanity observed by Glees and Griffith (1952). In the history the Korsakovian elements-fabricated stories about the present borrowed from past elements and misrecognitionwere clearly distinguished. At necropsy the gyri hippocampi were seen to be completely destroyed on both sides, as was the gyrus fusiformis with degenerated fornix; the mammillary bodies were normal. The case reported by Conrad and Ule (1951) is less significant as the lesions of Ammon's horns were accompanied by transneuronal degeneration of the mammillary bodies. Ritchie Russell and Espir (1961) reported several cases of wounds of the hippocampal system with loss of memory.

The experimental proof of the influence of the gyri hippocampi was provided by the partial temporal lobectomies made by Scoville and Milner (1957). These authors in eight patients made a more or less extensive resection of the internal side of the temporal lobes, including the uncus and the foremost two-thirds of the gyri hippocampi. They assessed retrograde amnesia and found a severe defect of memorizing. This finding was confirmed by Penfield and Milner (1958) who reached the same results in two cases following a similar resection, but on one side only. They thought that in both cases the gyrus hippocampi on the opposite side must have been abnormal and abnormality was supported by E.E.G. studies. It seems that the bilateral aspect of the lesions 
is an absolute requirement, as these authors never noted memory disorders in 80 other cases of similar temporal lobectomy on one side only. However, Ritchie Russell and Espir (1961) think that lesions of the hippocampus in the dominant side of the brain may be particularly important for memorizing.

An analysis of these case histories shows that the memory disorders in such patients make them unable to repeat a story or to identify three items pointed out to them a few minutes earlier. Their perception and immediate memory capabilities are normal, and so are their formerly acquired memories as testified by their retaining, not only past memories, but their language and individual professional abilities. In such patients, there is no fabrication but their answers show a certain amount of paramnesia and some erroneous interpretations. Here again, some retrograde amnesia had been demonstrated for the period preceding surgery. Therefore, this type of operation achieves an actual surgical syndrome of Korsakoff in which there is a pure deficiency in memorizing recent facts with little fabrication and euphoria.

These findings clearly indicate the part played in man's memory by the mammillary bodies and the gyri hippocampi. Considering the close anatomical connexions between the structures of the hippocampus and the mammillary bodies linked by the fornix, of which one is the foremost and the other the hindmost part (Fig. 1), it is tempting to view the whole as an integral system. Nevertheless, severing the anterior pillar of the fornix on both sides involved no disorder of memory in the patients of Dott (cited by Ule, 1900) and of Cairns and Mosberg (1951).

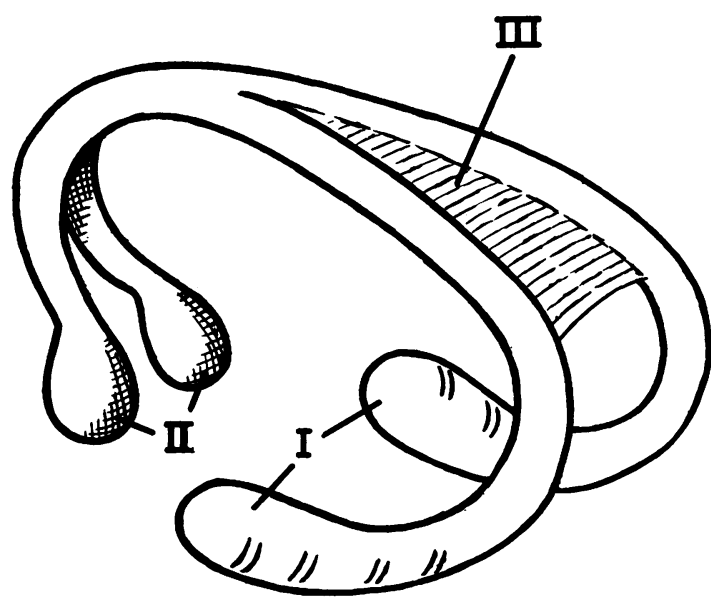

FIG. 1. Diagram of the fornix. I Hippocampus; II mammillary bodies; III hippocampal commissure.
From this anatomical and clinical survey we are in agreement with Delay, Brion, and Elissalde (1958 a and $b$ ) that the integrity of the mammillary bodies and of other structures anatomically connected to them, especially Ammon's horns, are essential in man to subserve this special function of memory, the memorizing of recent facts.

\section{PHYSIOPATHOLOGY}

The basic disorder in this defect of memorizing is the impossibility of using present stimuli in a delayed manner so as to memorize them for integration into the whole sum of past acquirements. This inability to memorize new elements prevents the patients acquiring new information so that the old will be the only available knowledge. It is therefore possible to identify the onset of the pathological disorder by careful questioning, running backward in time to those periods when memories were properly fixed. This is especially clear after trauma where lesions have appeared abruptly, but it can also be evinced in cases of more gradually appearing lesions, as in some alcoholic encephalopathies, byo questioning both the patient and his family. Thus, patient will retain a clear memory of his childhood and military life and a dimmer memory two or three을 을 years after becoming a bartender; a woman will calb up recollections of her life up to the time of her husband's death and is barely capable of fragmentaris data from the very period when she took to drinking $\overrightarrow{0}$ Once this disorder is complete and permanent the retrograde amnesia involved keeps increasing. Other patients in whom lesions are less severe or have partly subsided, as happens in some alcoholic cases which react to thiamine, may retain a certain rate of memorizing and preserve some new facts, although most often few in number and after much repetition.

In contrast to this basic disorder, pure forms of Korsakoff's syndrome allow of the absence of perception disorders when the patient retains his ability to grasp the present situation, any familiar object, word, or person being readily identified. Memory acquirements recorded before the lesions are retained, as evinced by the preservation of language, of past memories, of past techniques and habits. Let us quote again the case of Korsakoff's chess player who 8 could tackle on the chessboard any new situation $₹$ calling upon the familiar tactics but was unable to 의 learn the rules of a simple new game. The capabilities of immediate memory remain normal, as the patient is able to remember a series of six or seven digits.

In the present state of our knowledge, therefore, or we can accept the view that this type of deficiency is $N$ related to bilateral lesions of the hippocampus- N mammillary system, and it can occur as much from 
lesions of the mammillary bodies as from both gyri hippocampi.

The various pathological degenerations which may affect both structures are often more widespread, and associated lesions either in the neighbouring grey structures or more diffusely affecting the cortex and the whole brain will result in numerous cases in which there is confusion or psychosis and in which the memory disorder will exist, but it will lose its autonomy and will be overshadowed in the picture of more general deterioration.

This leads us to the study of the physiopathological processes in symptoms which often accompany a defect of memorizing, viz., misrecognitions and disorientations, which have been considered as integral to Korsakoff's syndrome. It should be recalled in the first place that such companion disorders are lacking in many cases. The patient is aware of the disorder in his memory and, like my patient Emilienne, affirms that 'it all fades away'. When such disorders exist, they may appear in a variety of forms: from occasional paramnesia and misrecognition suggested by the doctor, with the patient approving without being sure of his answer, to severe fabrication delirium associated with disorientation in time and space, and to important disorders in temper and consciousness.

Various physiopathological processes may be mentioned. Some see this as an active process, a compensatory attempt to re-create a seemingly consistent psychological content in spite of the severe memory gaps involved by existing memorizing and recollection disorders. Such is the opinion of Pick (1915), who stresses the unconscious need to fill the gaps of thought, whence the 'compensatory' feature in fabrication. Such is also the opinion of Jaspers (1933) who considers such patients unable to reach an accurate result on account of their loss of basic associations. They unwittingly make up what seems the most likely to them.

We think in fact that a Korsakovian reacts to the present situation with what he has, that is, with his stock of past memories, because he has nothing else. Stimulation will act as extracting stimuli which will start old neuronal patterns acquired before the mammillo-hippocampal lesion. Only in the incomplete syndrome does one observe an attempt to use some recent acquirements which, confronted with past ones, result in a fabricated reconstruction of a story from the recent past.

Whatever the process involved, another factor enters: the patient's previous personality. The amnesic's mental activity proceeds from his knowledge, ideas, feelings, emotions, and instincts. The quality of the disorder is likely to vary according to types of personality and of background. Moreover, such is the opinion of Flament who has shown how 4 a personality's deepest urges would influence the content of the fabrications.

The part played by each of these factors-disorder of memorizing, of recollection, desire for compensation, and the patient's previous personalitywill vary in every case, which explains the wide discrepancy in the case histories studied. They can be roughly classified as: 1 pure amnésie de mémoration; 2 amnésie de mémoration with fabrication and disorientation; and 3 amnésie de mémoration associated with various grades of aphasia, apraxia, and agnosia.

OPERATION OF MEMORY As this pathology indicates a dissociation between the capacity to memorize and the preservation of old memories, it is suggested that there must be different structures in the brain for these two varieties of remembering. It seems that the hippocampo-mammillary system is essential for memorizing whereas retention of old information requires the integrity of the neuronal, cortical, and subcortical areas which support memorized activities, say praxic, gnostic, or motor skill, or, to put it in a different way, sensory, intellectual, or motor.

We may assume that the reshuffling of the numerous stimulations which reach us at the same timesome being inhibited, others reinforced-produces a 'common final stimulation' (to apply in the sensory field an expression used by Sherrington for motion) that reaches the brain. It seems that the integrity of the cortex is essential for its conscious perception, as localized degradations of the cortex result in specific deteriorations of perception (agnosia of sight, hearing). This common final stimulation is a dynamic impulse, therefore, endowed with an immediate future which may be thought of as of two types. The impulse acts as an extracting stimulus, when it actuates a previously memorized circuit which will operate to yield, according to the mosaics of its component nerve cells, either a motor, emotional, or verbal answer, or a sensation, or a recognition, these various activities embodying a conscious attitude adapted to the situation which gave rise to the stimuli. In this case, consciousness hardly records the extracting stimulus itself but rather the whole pattern of perceptions and reactions it involves. In all the above cases, the common final stimulation actually alters the subject's train of thought or action but does not enrich his stock of knowledge. It actuates old circuits without creating new ones. In other circumstances, the information contained in the common final stimulation is not used immediately but stored for subsequent availability. It is a conscious activity. The new information does not alter the present situation, but goes to increase the stock of memories. 
In this case, new circuits must be created. Of course, if both processes can occur independently, in normal subjects this common final stimulation is very likely to result in a joint action and to start an immediate reaction while it integrates into a new circuit connected to old structures.

One fact to emphasize is that the study of Korsakoff's syndrome and its defect of memorizing is the only one to allow the identification of both types of reaction, thanks to the dissociation it involves.

THE MECHANISM OF MEMORIZING The hippocampus, fornix, and mammillary bodies are elements in a more extensive circuit reaching from the mammillary bodies through Vicq d'Azyr's bundle to the anterior thalamic nuclei and from there to the cingular cortex. The cortico-cortical circuit thus connects the temporal cortex to the cingular one with an exchange with the opposite hemisphere through the fornix (f ig. 2). Papez (1942) confirmed its autonomy on cmbroyological grounds and Grünthal (1923) with ; hylogenetic arguments. According to Grünthal, the mammillary bodies hold a very special position in the hypothalamus; they should not be considered as part of its vegetative structure but actually belong to a recently implanted autonomous system. Whereas Papez initially thought that this circuit was the theoretical anatomical basis of emotion, we know today that lesions of the mammillary bodies and of the hippocampus mostly result in amnesic disorders. This brought Benedek and Juba (1941), and later on Orthner (1957), to agree that Papez' circuit plays a role in memory functions.
There is an obvious risk in being too adventurous, and we know the outcome of considering various circuits as supports of different functions, whether of language or motion coordination. Nevertheless, Papez' circuit is an anatomical identity which connects the temporal and cingulo-frontal cortex of both hemispheres and its interruption, as long as it is a bilateral one, at the levels of Ammon's horns and of the mammillary bodies, and prevents the memorizing of recent facts.

Let us now come back to the functional aspect of the phenomenon of memorizing.

The volley of sensory influx represented by the common final stimulation has but a limited life; unused or overlooked it can no longer be used, e.g., the forgotten actions of the driver unable to remember how many times he has used the brake or the gears during a given journey. It would be the proper role of the hippocampo-mammillar structures, as components in cortico-cortical association circuits, to retain such information and to effect an active integration by bringing the new information closer to one of several previously memorized elements. In fact, we remember new information in relation to old information, and it is exactly at the point where we have located it that we shall come and look $\mathrm{N}$ for it later on. The more carefully the structural $\stackrel{\square}{\circ}$ 을 work has been thought out, that is, the more connecting points and bridges that have been established $\frac{7}{5}$ with old acquirements, the more efficient the fixation and the easier the recollection. In this respect, we understand the significance of repetitions which willo of give better structural opportunities, and the role of

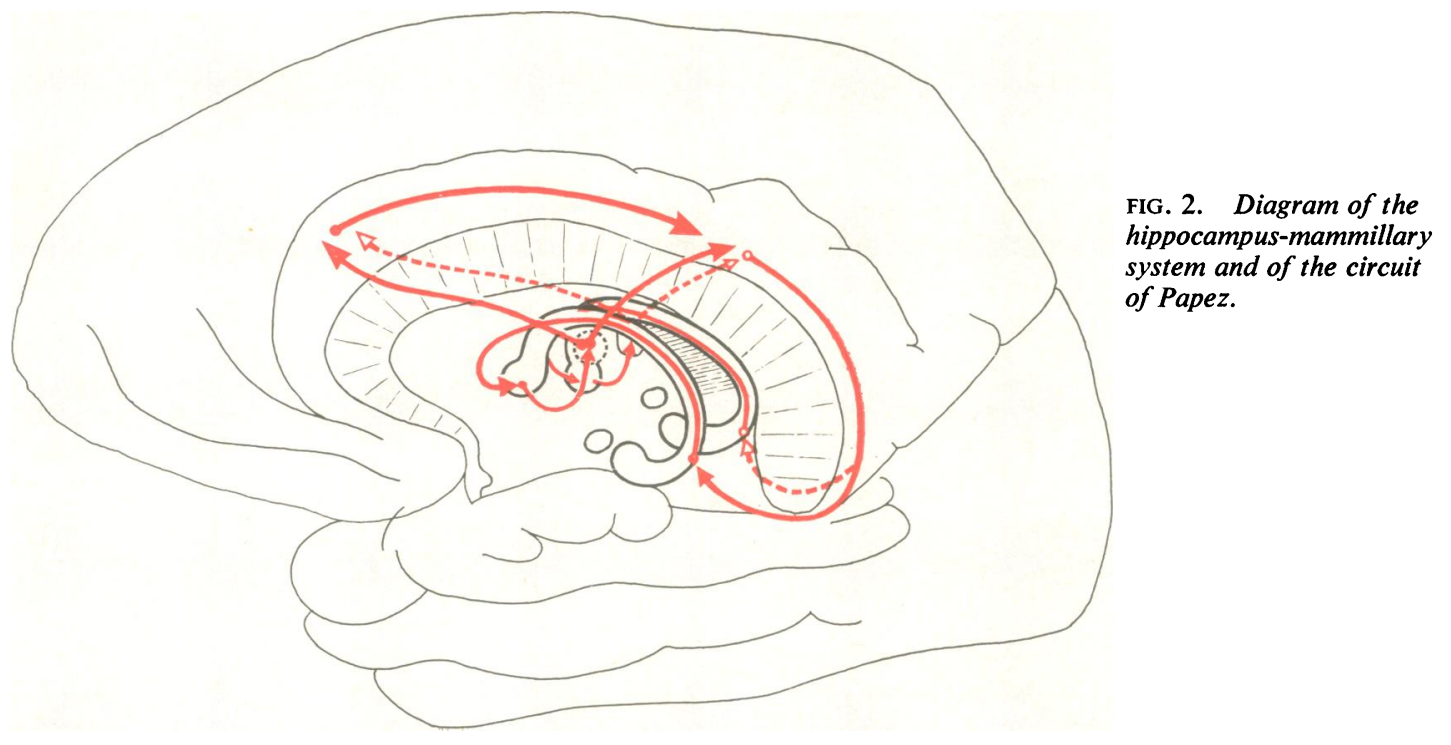


structures which, owing to their central site and their anatomical connexions, provide for the 'circulation' of information as long as is necessary for its integration in cortical and subcortical circuits which support acquired activities, i.e., memorized ones. Remembering is a complex activity which, in order to select what will be remembered, calls upon stocked notions, whether deep emotional motivations or 'reasons', both depending on previous acquisitions. This shows the complexity of the structures involved in memory, but, among them, the hippocampo-mammillary system plays a major role since its destruction selectively prevents memorizing.

\section{SUMMARY}

Defect of memorizing (amnésie de mémoration), first described by Korsakoff (1889), is characterized by the inability to acquire new memories as opposed to the preservation of previously fixed ones. This condition is frequently accompanied by fabrication with misrecognition and disorientation. On account of the deficiency of memorizing, the patient acquires no new memories and this gap will broaden from day to day as a retrograde amnesia. Unable as he is to retain new elements, the patient lives on the memory stock fixed before his illness, and this is often wholly preserved. Fabrication is a consequence of such amnesia; a Korsakovian reacts to a new situation with what he has, that is, with his stock of old memories, because he has no others. In incomplete forms only, an attempt to use new certain acquisitions may be found.

Amnésie de mémoration is often found in its pure form, but it can coexist with confusion or insanity in which it is but one element.

Amnésie de mémoration appears in various aetiological circumstances: chronic alcoholism, by way of deficiency processes; toxic or infectious encephalopathy; Wernicke's presbyophrenia; skull trauma; tumours of the base of the brain. It is also found in bilateral surgical excision of the hippocampus. This implies that this syndrome does not depend on the cause but on the location of the lesions.

It seems that two structures, the mammillary bodies and the hippocampus, play a predominant role in defects of memorizing, whereas old memories require the integrity of various cortical and subcortical areas.

Thus an organized sensory stimulation is likely to start a joint action in normal subjects, viz., an immediate reaction plus the integration to a new circuit related to old memories. The study of Korsakoff's syndrome and of amnésie de mémoration, owing to the dissociation it brings about, helps to identify and separate both types of reaction.

\section{REFERENCES}

Angelergues, R. (1958). Rapport au Congrès de Psychiatrie et de Neurologie de Langue Française, p. 83-175. 56th session, Strasbourg.

Baruk, H. (1926). Les Troubles Mentaux dans les Tumeurs Cérébrales, vol. 1, p. 396. Doin, Paris.

Bender, L., Curran, F. J., and Schilder, P. (1938). Arch. Neurol. Psychiat. (Chicago), 39, 482.

Bender, M. B., Furlow, L. T., and Teuber, H. L. (1949). Confin. neurol. (Basel), 9, 140.

Benedek, L., and Juba, A. (1941). Arch. Psychiat. Nervenkr., 114, 366. Bessières, R. (1948). Encéphale, 37, 313.

Bonhoeffer, K. (1904). Allg. Z. Psychiat., 61, 744.

Bouttier, H. P. R. (1918). Contribution à l'étude neurophysiologique des traumatismes cérébraux récents. Thèse, Médecine, vol. 1, p. 248. Paris.

Cairns, H., and Mosberg, W. H. (1951). Surg. Gynec. Obstet., 92, 545 .

Campbell, A. C. P., and Biggart, J. H. (1939). J. Path. Bact., 48, 245.

Chaslin, P. (1895). La Confusion Mentale Primitive. Asselin and Houzeau, Paris.

(1912). Eléments de Clinique et de Séméiologie Mentales, vol. 1, p. 956. Asselin and Houzeau, Paris.

Conrad, K., and Ule, G. (1951). Disch. Z. Nervenheilk., 165, 430.

Delay, J. (1942). Les Dissolutions de la Mémoire, vol. 1, p. 152. P.U.F., Paris.

, Brion, S., and Elissalde, B. (1958a). Presse méd., 66, 1849.

- _ (1958b). Ibid., 66, 1965.

Dott, N. M. (1900). Cited by Ule, G.

Dupré, E. (1903). In Traité de Pathologie Mentale, edited by Gilbert Ballet, pp. 1122-1160. Doin, Paris.

Ey, H. (1954). Etudes psychiatriques. Structure des Psychoses aigues et Déstructuration de la Conscience, p. 373. Brouwer, Paris.

Flament, J. (1957). Acta neurol. belg., 57, 119.

Gamper, E. (1928). Dtsch. Z. Nervenheilk., 102, 122.

Glees, P., and Griffith, H. B. (1952). Mschr. Psychiat. Neurol., 123 193.

Grünthal, E. (1923). Ibid., 53, 89.

(1947). Ibid., 113, 1.

Gudden, H. (1896). Arch. Psychiat. Nervenkr., 28, 643.

Jaspers, K. (1933). In Psychopathologie Generale, translated by A. Kastler and J. Mendousse, vol. 1, p. 632. Alcan, Paris.

Kalberlah, F. (1904). Arch. Psychiat. Nervenkr., 38, 402.

Kleist, K. (1934). Gehirnpathologie, vol. 1, p. 1408. Barth, Leipzig.

Korsakoff, S. S. (1889). Medizinskioje Obozrenije, 31. Translated by M. Victor and P. I. Yakovlev.

(1889). Rev. philosophique de la France et de l'Etranger (Paris), 28, 501 .

- and Serbsky (1892). Arch. Psychiat. Nervenheilk., 23, 112.

Malamud, N., and Skillicorn, S. A. (1956)., Arch. Neurol. Psychiat. A.M.A. 76, 585 .

Orthner, H. (1957). 11th International Congress of Neurologica Sciences, Brussels, vol. 2, pp. 77-96.

Papez, J. W. (1942). A.K.N.M.D., 20, 21.

Penfield, W., and Milner, B. (1958). A.M.A. Arch. Neurol. Psychiat., $79,475$.

Pick, A. (1915). Z. ges. Neurol. Psychiat., 28, 344.

Régis, E. (1923). Précis de Psychiatrie, 6th ed. Doin, Paris.

Roussy, and Lhermitte, J. (1916). Les Psychonévroses de Guerre, vol. 1. Masson, Paris.

Russell, W. Ritchie (1959). Brain, Memory, Learning. Clarendonl Press, London.

- , and Espir, M. L. E. (1961). Traumatic Aphasia. Oxford University Press, London.

Scoville, W. B., and Milner, B. (1957). J. Neurol. Neurosurg. Psychiat., $20,11$.

Seglas, J. (1895). Leçons Cliniques sur les Maladies Mentales et Nerveuses, vol. 1, p. 831. Asselin and Houzeau, Paris.

Terzian, H., and Dalle Ore, G. (1955). Neurology (Minneap.), 5, 373. von Czechmanek, K. (1954). Nervenarzt, 25, 158.

Walker, A. E. (1957). A.M.A. Arch. Neurol. Psychiat., 78, 543.

Williams, M., and Pennybacker, J. (1954). J. Neurol. Neurosurg. Psychiat., 17, 115. 